\title{
Comment on the Geometry of the Circle of Willis Anatomical Variants as a Potential Cerebrovascular Risk Factor
}

\author{
Abigail RAMOS, Alejandro QUIROGA-GARZA, Bernardo Alfonso FERNANDEZ-RODARTE, \\ Rodrigo Enrique ELIZONDO-OMAÑA, Santos GUZMÁN-LÓPEZ \\ Universidad Autonoma de Nuevo Leon, Facultad de Medicina, Human Anatomy Department, Monterrey, Mexico
}

Corresponding author: Alejandro QUIROGA-GARZA dr.aquirogag@gmail.com

To the Editor:

We sincerely applaud the work done by Pascalau et al. in which the anatomical variants and geometrical parameters of the Circle of Willis were correlated with their hemodynamic effects to identify possible risk factors for neurological disease (3). This work is of the utmost importance since it uses mathematical models to assess brain perfusion and wall shear stress by evaluating geometry and blood vessel characteristics.

The study provides a beneficial mathematical model to calculate the risk factor for intracranial aneurysms in patients with specific anatomical variants. The model proposed by Pascalau et al. evaluated blood flow resistance according to vessel size, calculated with the Hagen-Poiseuille law. The results of the study determined that the posterior cerebral circulation was a high risk system for aneurysms and that the anterior cerebral system was low risk. However, there is a much higher prevalence of aneurysms reported in the anterior cerebral system (2), contrary to what is suggested as high risk. The model, although relevant to flow, lacks consideration of vessel wall thickness as suggested by the Law of Laplace, which is important when considering flow pressure adaptation (1).
The mathematical model proposed by Pascalau et al. is of great importance in clinical practice to estimate the risk factor for intracranial aneurysms by analyzing blood viscosity, length, and luminal radius of the vessel to calculate flow resistance, conductance, and percentage departure from optimality, providing essential information to the physician. We consider it important to include vessel wall thickness in the model to calculate a risk that results in a better correlation with clinical scenarios.

\section{REFERENCES}

1. Nasimi A: Hemodynamics. In: Gaze DC (ed), The Cardiovascular System-Physiology, Diagnostics and Clinical Implications. London: Intech Open Limited, 2012:95-108

2. Orakdogen M, Emon ST, Somay $H$, Engin $\mathrm{T}$, Is $\mathrm{M}$, Hakan $\mathrm{T}$ : Vascular variations associated with intracranial aneurysms. Turk Neurosurg 27:853-862,2016

3. Pascalau R, Padurean VA, Bartos D, Bartos A, Szabo BA: The geometry of the circle of Willis anatomical variants as a potential cerebrovascular risk factor. Turk Neurosurg 29(2):151-158, 2019
Bernardo Alfonso FERNANDEZ-RODARTE (10): 0000-0002-3527-1922
Rodrigo Enrique ELIZONDO-OMAÑA (1) : 0000-0002-8017-2640 Santos GUZMÁN-LÓPEZ
(D) : 0000-0002-0018-4319 